\title{
High-Purity Nanopowders for Laser Applications
}

\author{
Deepak Ganta, Ganesh Venugopal, Andrew T. Hunt, and Michael Sapp
}

nGimat LLC., 2436 Over Drive, Suite B, Lexington, KY 40511, USA

Correspondence should be addressed to Ganesh Venugopal, gvenugopal@ngimat.com

Received 26 January 2012; Accepted 28 February 2012

Academic Editors: C.-C. Chen, A. N. Obraztsov, and A. Patra

Copyright () 2012 Deepak Ganta et al. This is an open access article distributed under the Creative Commons Attribution License, which permits unrestricted use, distribution, and reproduction in any medium, provided the original work is properly cited.

\begin{abstract}
We have successfully developed high-quality laser-grade yttrium aluminum garnet (YAG), and lutetium oxide ( $\left.\mathrm{Lu}_{2} \mathrm{O}_{3}\right)$, using a novel combustion chemical vapor condensation (CCVC) technique based on a proprietary NanoSpray Combustion process. The purity of the nanopowders was $>99 \%$. Nanopowders with different dopants have been synthesized over a 10-200 nm size range, with low-cost, high-purity precursors that are viable for large-scale production. Great strides have also been made in developing highly dense ( $>99 \%$ theoretical density) polycrystalline Nd-doped YAG pellets using vacuum sintering and hot isostatic pressing (HIP). This method is an alternative to the Czochralski method for making single-crystal ceramic bodies, which has several disadvantages including high cost, size, shape restrictions, and limitations in Nd concentrations $(\sim 1$ at $\%)$. Nanomaterials also enable higher percentages of Nd to be incorporated into the YAG lattice which improves laser efficiency and $>85 \%$ near IR transmission, thereby reducing scattering losses associated with larger grain-size polycrystalline materials.
\end{abstract}

\section{Introduction}

In a little over a decade, ceramic-laser hosts have proven themselves as being a promising option for enabling highpower solid-state laser systems at significantly lower costs compared to single-crystal gain medium. Yttrium aluminum garnet (YAG) has emerged as the most widely produced laser gain host and has enjoyed popularity as a substrate material for optical components. The YAG host is a stable compound, mechanically robust, physically hard, optically isotropic, and transparent from below $300 \mathrm{~nm}$ to beyond 4 microns. The industry-standard Czochralski process, while successful for making single crystal materials like (YAG), is very expensive and energy intensive as it needs the raw material to be heated to temperature above the melting point of the material (typically $\geq 2000^{\circ} \mathrm{C}$ ) [1]. The single crystals are also limited in terms of the size and shape that they can be formed in [2]. In addition, solubility of rare earth dopants in some single crystals is limited because of segregation of the dopants. For example, the solubility of $\mathrm{Nd}$ is limited to 1 at $\%$ in YAG single crystals during growth [3]. Thus, efficient absorption of the excitation is limited, and it is difficult to fabricate a high-efficiency and high-power laser even with the maximum size of single crystals available [4]. On the other hand, polycrystalline ceramic laser materials can be fabricated at relatively low temperatures $\left(<1800^{\circ} \mathrm{C}\right)$ and are only limited in size by the sintering ovens that are used to densify them. Some optimized sintered laser ceramics even demonstrated equal or superior optical quality compared with conventional laser single crystal [5]. Furthermore, the use of nanopowders with homogenous composition within each particle allows for uniform distribution of dopants in the ensuing ceramic body. A YAG-based lasing system made from nanopowders could be run at higher output energies, high optical transmission, and have improved thermal stability.

Recently, Yb-doped crystalline sesquioxides $\mathrm{Yb}^{3+}: \mathrm{Y}_{2} \mathrm{O}_{3}$, $\mathrm{Yb}^{3+}: \mathrm{Sc}_{2} \mathrm{O}_{3}$, and $\mathrm{Yb}^{3+}: \mathrm{Lu}_{2} \mathrm{O}_{3}$ have proved to be very attractive gain media for high-power femtosecond lasers since they have excellent thermal-mechanic properties [6]. For example, the thermal conductivity for $\mathrm{Lu}_{2} \mathrm{O}_{3}$ single crystal is reported to be $12.5 \mathrm{~W} / \mathrm{mK}$. Although the thermal conductivities depend on the concentration of $\mathrm{Yb}^{3+}$ ions, these sesquioxides are still considered to be of higher thermal conductivity than that of Yb:YAG with the same doping level. Among them, $\mathrm{Yb}^{3+}: \mathrm{Lu}_{2} \mathrm{O}_{3}$ single crystal has the highest thermal conductivity of $11 \mathrm{~W} / \mathrm{mK}$ with $\mathrm{Yb}$ doping ( $\mathrm{Yb}$ concentrations of 2.7 at $\%$ ), while that value of $\mathrm{Yb}: \mathrm{YAG}$ at the 
same doping level is about $6.8 \mathrm{~W} / \mathrm{mK}$ [7]. Due to the high

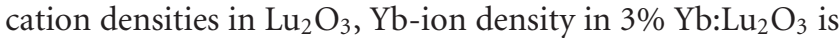
comparable to that density in 5\% Yb:YAG [8].

Many techniques have been used to synthesize nanopowders, including coprecipitation, gel entrapment, hydrothermal, and spray pyrolysis [9-13]. The enabling NanoSpray Combustion process used to make the nanopowders discussed in this publication is proprietary to $n$ Gimat. It is an outbranch of $n$ Gimat's combustion chemical vapor deposition (CCVD) process which has been demonstrated to create thin films of many different compositions at a high rate for low cost $[14,15]$. While CCVD process can be used to form nanostructured thin films, the version of this process that is used to make nanopowders is referred to as combustion chemical vapor condensation (CCVC). Both processes make use of inexpensive precursor chemicals in solution, without having to resort to costly and bulky furnaces, vacuum equipment, and reaction chambers. More often than not, as-made films or nanopowders are suitable for the application, thereby minimizing the need for timeconsuming postdeposition or postcollection treatments. These compelling advantages of the $n$ Gimat NanoSpray Combustion technique offer great potential to manufacture better and lower cost nanopowders than competing methods such as solution-precipitation, spray-pyrolysis, traditional CVD, and plasma-arc techniques. By controlling the homogeneous nucleation/condensation of vapor emitted from the NanoSpray Combustion flame, we are able to produce highquality nanopowders.

\section{Synthesis of Nanopowders}

When used in CCVC mode, the NanoSpray Combustion synthesis method (Figure 1) can be summarized in the following four steps: (1) metering of the precursor solution and process gases into the Nanomiser Device, (2) atomization of the precursor solution to produce submicron droplets, (3) combustion processing of the resulting vapors to form nanopowder, and (4) collection of the nanopowder in dry form or as a colloidal dispersion.

During the initial steps, chemical precursors such as metal nitrates or metal carboxylates are dissolved in suitable solvents, which also act as a fuel for combustion. Watersoluble precursors may also be dissolved in water and then mixed with a suitable liquid or vapor fuel. The chemical precursor solution is atomized to a submicron level with the proprietary Nanomiser Device, and the atomized droplets are then mixed with the oxidizer and ignited to generate a flame. The flame flash vaporizes the solvent and the precursors then decompose and condense to form the nanoparticles as shown in Figure 2. The number and the size of nuclei formed in the flame are a function of the solution density, viscosity, surface tension, and concentration. The synthesized nanoparticles are then captured in dry (powder) or wet (dispersion) product form. In contrast to conventional spray flame pyrolysis, $n$ Gimat's CCVC process is able to produce nanopowders with grain sizes less than $10 \mathrm{~nm}$ or controlled to be larger up to about $150 \mathrm{~nm}$. By adjusting

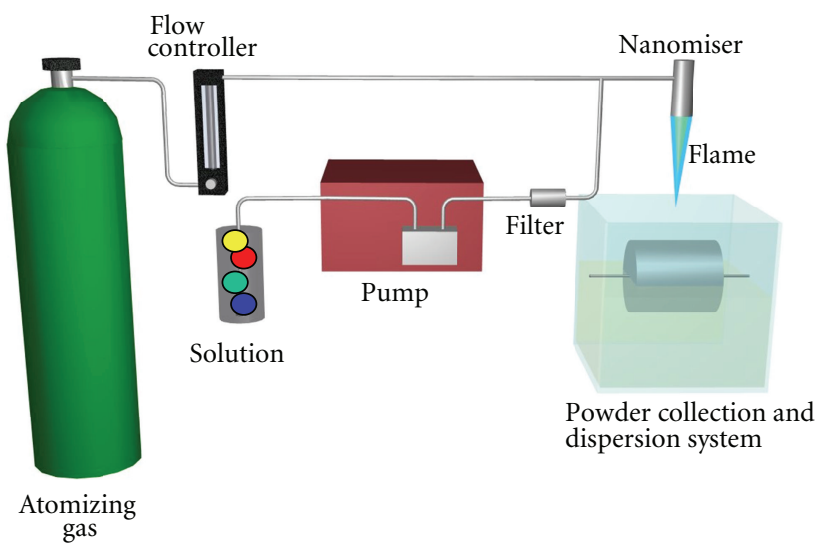

Figure 1: Schematic representation of NanoSpray combustion System as used in CCVC mode.

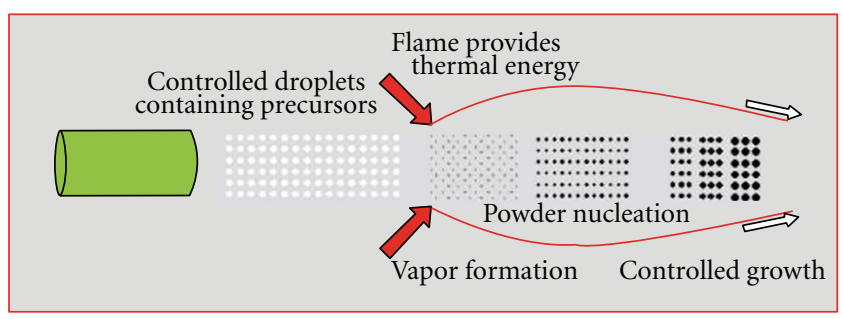

FIgURE 2: Schematic of nanoparticle production via the NanoSpray Combustion process.

precursor solution concentrations and constituents, a wide range of nanopowder stoichiometries and compositions can be achieved. This flexibility is especially valuable for generating the complex multimetal compositions with unique nanopowder characteristics. Furthermore, surface composition of the nanopowders can also be tailored by judicious selection of precursor composition and process conditions.

During the flame synthesis, controlled thermal decomposition of the precursor results in the formation of metal and/or oxide vapors that consist of gaseous atoms, ions, and molecular-oxide species (e.g., M-O "monomers," $<5 \AA$ in size), which react to form atomic clusters (e.g., $(\mathrm{M}-\mathrm{O})_{x}$, where $x \sim 10$ and the cluster is $<5 \mathrm{~nm}$ in size) that then may condense (coalesce) to form particles with a size distribution in any range from 2 to $150 \mathrm{~nm}[15,16]$. Depending on the flame temperature and the position in the flame where powder is collected, nonagglomerated particles can be readily produced. The maximum flame temperature is in the range of $1600-2000^{\circ} \mathrm{C}$, depending on the solvent, precursor loading, and the Nanomiser Device atomization power. By using a reducing atmosphere, a number of metal nanopowders can be produced. The precursor composition and process conditions influence the nanopowder composition, as well as the nanopowder size and morphology. More than 100 nanopowder compositions have been fabricated by the NanoSpray Combustion method, including ceria $\left(\mathrm{CeO}_{2}\right), \mathrm{Ba}_{0.5}-\mathrm{Sr}_{0.5}-\mathrm{TiO}_{3}$ (BST), platinum, palladium, and silver nanopowders. 
Precursor solutions for YAG and $\mathrm{Lu}_{2} \mathrm{O}_{3}$ (LO) nanopowders were formulated by dissolving metal-nitrate, metalalkoxide, or metal-carboxylate compounds of the appropriate metals (and dopants) into nonaqueous solvents. For $\mathrm{Y}$ and $\mathrm{Al}$, a high-purity yttrium carboxylate and a highpurity Aluminum alkoxide were dissolved in an organic solvent at the desired stoichiometry. The Yttrium carboxylate was synthesized in-house from high-purity Y-carbonate purchased from Metall Rare Earth Lt. (China). Metall Rare Earth also supplied us with $>99.99 \%$ lutetium carbonate for Lu-carboxylate synthesis and $>99.99 \%$ lutetium nitrate which could be directly dissolved into solution solvent for nanopowder production. In order to obtain a highpurity neodymium precursor, $\mathrm{Nd}_{2} \mathrm{O}_{3}$ (99.997\%, Alfa Aesar), was refluxed in a carboxylic acid to make Nd-carboxylate. Thermal analysis was performed using thermogravimetric analysis (TGA) to determine the quantity of various surface species on the precursor powders, water in particular. The water content of the $\mathrm{Lu}$ and $\mathrm{Yb}$ nitrates were particularly useful in determining precursor solution compositions for producing doped $\mathrm{Yb}-\mathrm{LO}$ nanopowders of the desired stoichiometry. The concentration of neodymium was obtained by TGA of the solution, to first evaporate the 2-ethylhexanoic acid and subsequently ash the $\mathrm{Nd}(2 \mathrm{eh})_{2}$ residue. The $\mathrm{wt} \%$ $\mathrm{Nd}$ was then calculated based on the weight of $\mathrm{Nd}_{2} \mathrm{O}_{3}$ ash remaining. XRF of the ash was compared to XRF of the standard impure ash and confirmed the absence of any unwanted impurities. In particular, the Nd precursor was tested for purity using XRF to detect presence of impurities like $\mathrm{Fe}$ and $\mathrm{Ce}$.

Using the above-mentioned precursors in nCCVC, we have successfully synthesized several different compositions of YAG and $\mathrm{Lu}_{2} \mathrm{O}_{3}$ nanopowders in doped and undoped form. The analysis of these nanopowders and their conversion to dense ceramics is discussed below.

\section{Analysis of Nanopowders}

The X-ray diffraction scans (XRD) scan for a Lu-carboxylatederived nanopowder in Figure 3 shows that the target $\mathrm{Lu}_{2} \mathrm{O}_{3}$ phase (ICDD-JCPDS no. 12-0728) was achieved, even in as-synthesized (before further processing) form. The BET (Brunauer, Emmett, and Teller) method was used to find the surface area for this sample, and it was found to be $19.6 \mathrm{~m}^{2} / \mathrm{g}$. This corresponds to an average particle size of $33 \mathrm{~nm}$, assuming a density of $9.42 \mathrm{~g} / \mathrm{cc}$ for $\mathrm{Lu}_{2} \mathrm{O}_{3}$. The Xray fluorescence (XRF) technique was primarily used for purity testing, and it showed no detectable impurity peaks so $>99 \%$ pure material was made. Heat treatment or sintering is done to enhance density, and in some cases it needed to get the required phase of the nanopowders, and it also helps in obtaining ceramic bodies.

Figure 4 demonstrates that as-made YAG is dominantly amorphous but turns crystalline upon sintering. The XRD of the sintered ceramic sample showed YAG phase (ICDDJCPDS no. 33-0040) with no secondary phases. The prominent peaks are labeled with their respective Miller indices.

The TEM image in Figure 5 shows the particle size of sintered YAG nanopowder to be in the range of $20-100 \mathrm{~nm}$.
The BET method was used to find particle size and in turn verified using TEM. Various particle sizes were made, but the smaller sizes $(<25 \mathrm{~nm})$ were more difficult to densify during the studies conducted.

\section{Pellet Fabrication and Characterization}

A slip-casting technique was used in order to make YAG preforms (green-bodies) for sintering studies. YAG nanopowder was dispersed in aqueous medium. The dispersion was then slip cast into a 1-square-inch pellet by using a $\mathrm{CaSO}_{4}$ sulfate mold. The pellet surfaces were smoothed with sand paper before sintering. The samples were placed in the furnace for 24 hours at $1600^{\circ} \mathrm{C}$ to make dense ceramic ready for final hot isostatic pressing (HIP), in order to make transparent pellet with high transmission. This sample showed a modest increase in transparency but developed a black cloud caused by oxygen deficiency in the center slightly off to one side. The YAG samples were "HIPed" at $1700^{\circ} \mathrm{C}$ for eight hours under a pressure of $200 \mathrm{MPa}$ of argon. This color disappeared during thermal etching at $1450^{\circ} \mathrm{C}$ in air. Defects that were visible as black spots in the vacuumsintered sample disappeared during HIPing. Figure 6 shows the YAG-nanopowder pellet before and after HIP, with the "HIPed" sample looking transparent and clear compared to the sample before treatment. Typical weight loss on heat treatment is less than $2 \%$. Figure 7(a) shows the SEM image of the microstructure of the resulting polycrystal following pressing and sintering, indicating that the YAG pellet is uniformly sintered with smooth texture. Similarly the YAG nanopowder is pressed, sintered, and polished to form pellet as shown in Figure 7(b). Polishing can lead to removal of the surface defects that may contribute to decreased transmission or even lower density.

Techniques for producing $\mathrm{Lu}_{2} \mathrm{O}_{3}$ ceramic green bodies were also evaluated, using pellet pressing and electrophoretic deposition (EPD). This is the simplest and fastest method, however, it is not known for producing highly dense objects due to trapped gas inclusions. Nanopowders were pressed in a mold at a pressure of around 2000 psi for 30 seconds. Samples, $2-4 \mathrm{~mm}$ in thickness and $13 \mathrm{~mm}$ in diameter, were achieved. The vacuum atmosphere was chosen under the assumption that interparticle pores with air could be minimized by the vacuum atmosphere thereby increasing density values. The sintering trials in air at $1700^{\circ} \mathrm{C}$ lead to density values ranging from $75 \%$ to $98 \%$ of full density. Multiple sintering steps and hot isostatic pressing (HIP) could be used to attain the high sintered body densities ( $>99 \%)$. In HIP, isostatic pressures as high as 45,000 psi were used to sinter the particles together. When carried out at temperatures as high as $1700^{\circ} \mathrm{C}$, this process is usually done under inert atmospheres. Achieving high-density sintered bodies out of $\mathrm{Lu}_{2} \mathrm{O}_{3}$ nanopowders is significantly more challenging, since $\mathrm{Lu}_{2} \mathrm{O}_{3}$ has a significantly higher melting temperature than YAG or $\mathrm{Y}_{2} \mathrm{O}_{3}$, which thereby demands higher sintering temperatures. More work is required to create dense ceramic lutetium-oxide bodies with transparency numbers similar to what we have achieved in YAG. 


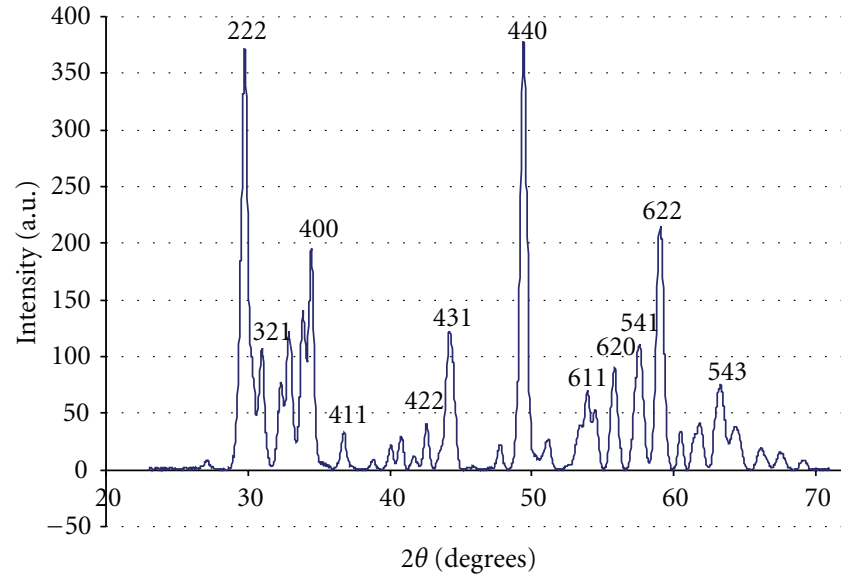

(a)

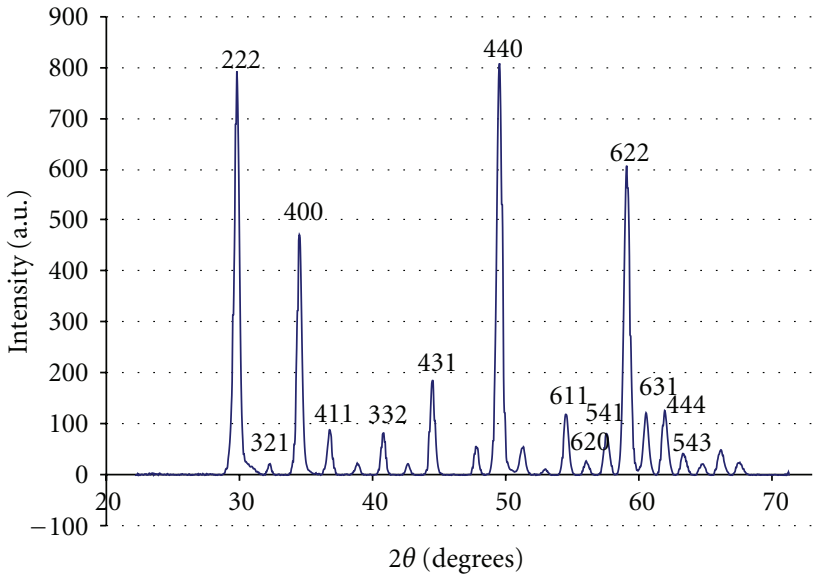

(b)

FIGURE 3: XRD for lutetium-oxide nanopowder synthesized by nCCVC (a) before and (b) after heat treatment at around $1200^{\circ} \mathrm{C}$. The peaks indicate pure lutetium phase and the reference PDF database file for $\mathrm{Lu}_{2} \mathrm{O}_{3}$ was used to label the larger peaks.

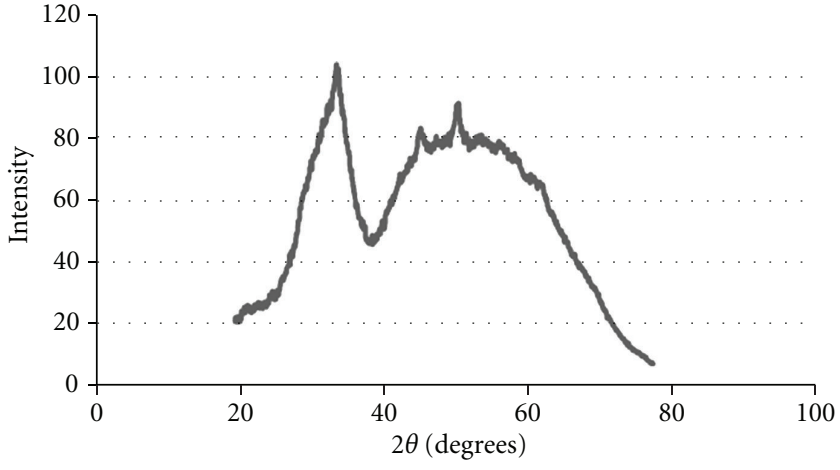

(a)

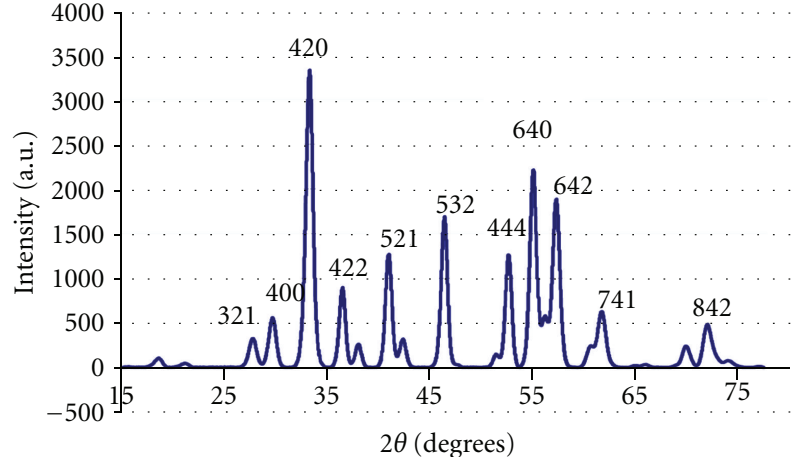

(b)

FIGURE 4: XRD for yttrium aluminum oxide nanopowder (a) before and (b) after heat treatment at around $1700^{\circ} \mathrm{C}$, leading to the formation of yttrium aluminum garnet (YAG) phase. The peaks after heat treatment indicate the YAG phase from the reference PDF database file.

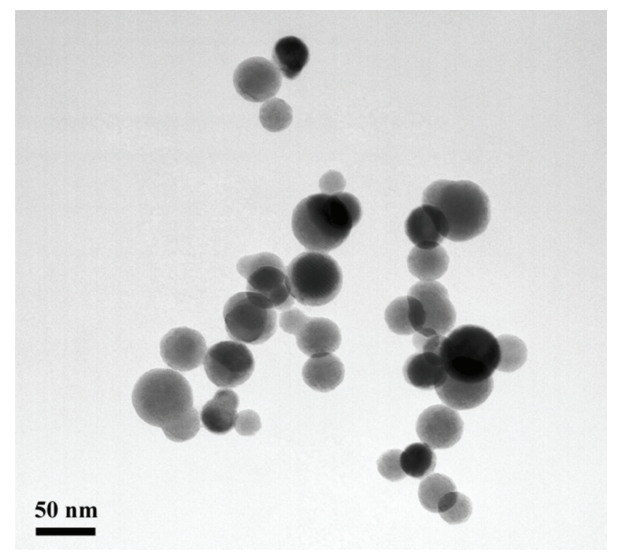

FIgURE 5: TEM image of as-made YAG nanopowder.

The YAG nanopowder used to produce optically transparent pellets was used to collect UV/Vis transmission spectra showing strong response at $1064 \mathrm{~nm}$. Laser testing was done and spectra collected using a $3 \mathrm{~mm}$ spot-size laser at $1024 \mathrm{~nm}$. Nd:YAG lasers typically emit light with a wavelength of $1064 \mathrm{~nm}$, in the infrared [17, 18]. We performed preliminary optical transparency measurements using a UV/Vis spectrometer, and we could observe optical transmission above $84 \%$ from 900 to $1450 \mathrm{~nm}$ as shown in Figure 8 from two batches of pellets labeled as 91A-2 and 91B-1. The initial test on slope efficiency is measured to be 0.14 , performed at an army research laboratory. More work needs to be done on further optical testing like scattering loss, and threshold for YAG and other nanopowder-based pellets.

\section{Conclusions}

In summary, we have successfully synthesized highpurity yttrium aluminum garnet (YAG) and lutetium-oxide $\left(\mathrm{Lu}_{2} \mathrm{O}_{3}\right)$ nanopowders in undoped and doped form $(1 \%$ $\mathrm{Nd}$ ) using novel combustion chemical vapor condensation (CCVC) technique with purity $>99.9 \%$. Precursor selection, precursor solution formulation, and process conditions 


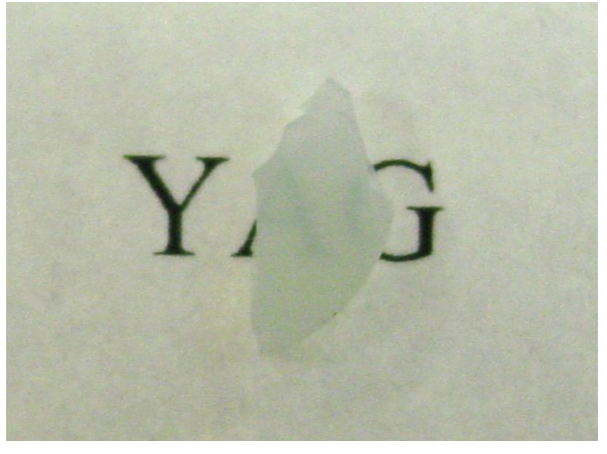

(a)

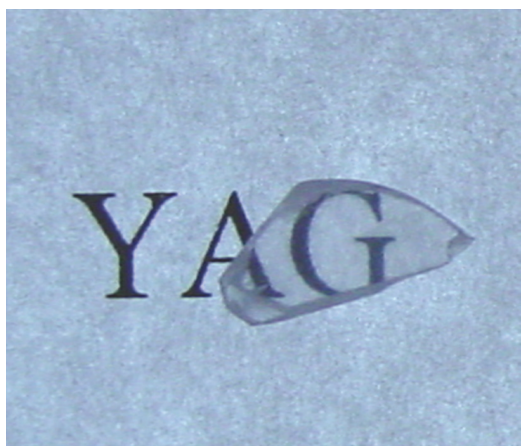

(b)

Figure 6: The YAG nanopowder pellet before (a) and (b) after HIP.

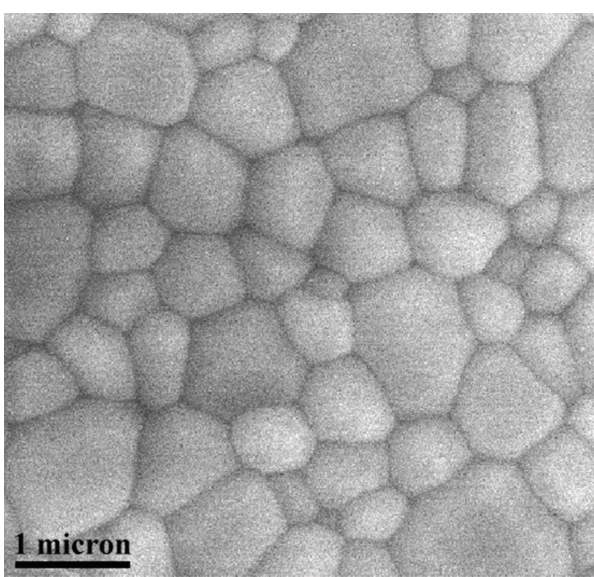

(a)

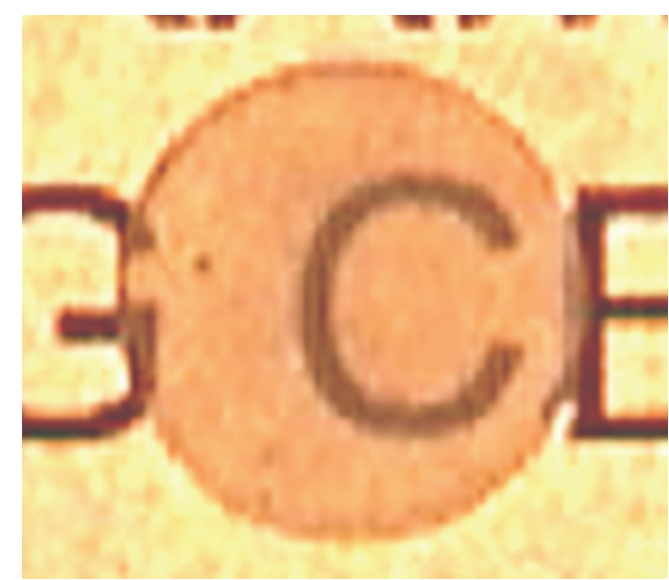

(b)

Figure 7: Picture showing YAG pellets. (a) SEM micrograph of YAG pellet sintered in air at $1700^{\circ} \mathrm{C}$ for 5 hours. (b) Pressed, sintered, and polished pellet made from YAG nanopowder.

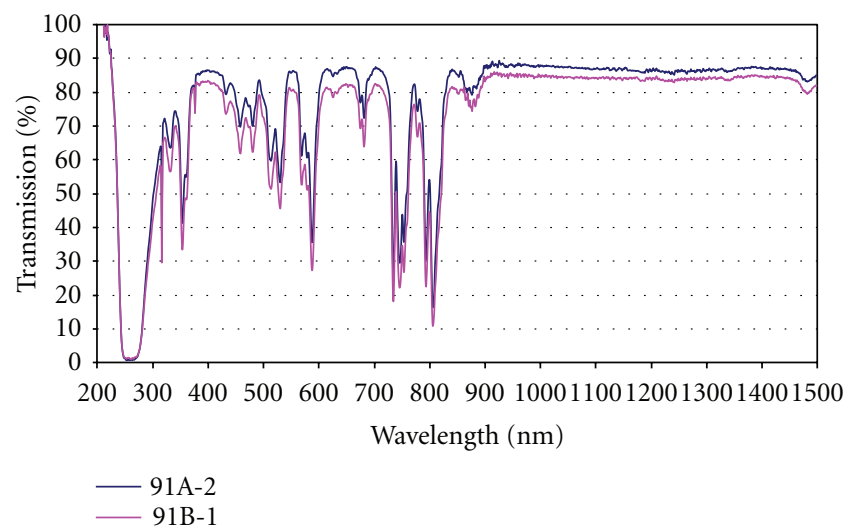

FIGURE 8: Optical transmission spectra for two batches of YAG pallets.

for combustion synthesis all play a critical role in the formation and characteristics of the nanopowders. Elemental and particle size analysis was done using XRD, XRF, BET, and STEM confirmed the targeted phases, purity and size. We also fabricated pellets from the nanopowders into a highly dense, $>99 \%$ ceramic bodies, and achieved translucent polycrystalline laser host materials with grain size less than $1 \mu \mathrm{m}$ and $>85 \%$ transmission at $1064 \mathrm{~nm}$, with a slope efficiency of 0.144 . Formation of these nanomaterials is desired for production of military and commercial High Energy Laser (HEL) systems.

\section{Acknowledgments}

This paper has been supported through an SBIR effort funded by the US Office of the Secretary of Defense. The authors would also like to thank Dr. Gary Messing at Pennsylvania State University and VLOC Inc., a subsidiary of II-VI Inc., and Raytheon for testing nanomaterials and giving valuable feedback. The authors would like to thank the associates who work with them on this project Zhihao Bao, Scott Flanagan, and Bala Sankaran.

\section{References}

[1] A. Ikesue and Y. L. Aung, "Ceramic laser materials," Nature Photonics, vol. 2, no. 12, pp. 721-727, 2008.

[2] A. Ikesue, K. Kamata, and K. Yoshida, "Effects of neodymium concentration on optical characteristics of polycrystalline 
Nd:YaG laser materials," Journal of the American Ceramic Society, vol. 79, no. 7, pp. 1921-1926, 1996.

[3] T. Sekino and Y. Sogabe, "Progress in the YAG crystal growth technique for solid state lasers," The Review of Laser Engineering, vol. 21, pp. 827-829, 1995.

[4] A. Ikesue, Y. L. Aung, T. Taira, T. Kamimura, K. Yoshida, and G. L. Messing, "Progress in ceramic lasers," Annual Review of Materials Research, vol. 36, pp. 397-429, 2006.

[5] H. Yagi, T. Yanagitani, K. Takaichi, K. I. Ueda, and A. A. Kaminskii, "Characterizations and laser performances of highly transparent Nd3+:Y3Al5O12 laser ceramics," Optical Materials, vol. 29, no. 10, pp. 1258-1262, 2007.

[6] V. Peters, A. Bolz, K. Petermann, and G. Huber, "Growth of high-melting sesquioxides by the heat exchanger method," Journal of Crystal Growth, vol. 237-239, no. 1-4, pp. 879-883, 2002.

[7] K. Contag, S. Erhard, and A. Giesen, "Calculation of optimum design parameters for Yb:YAG thin disk lasers," OSA Trends in Optics and Photonics, vol. 34, pp. 124-126, 2001.

[8] U. Griebner, V. Petrov, K. Petermann, and V. Peters, "Passively mode-locked $\mathrm{Yb}: \mathrm{Lu}_{2} \mathrm{O}_{3}$ laser," Optics Express, vol. 12, no. 14, pp. 3125-3130, 2004.

[9] R. V. Kamat, K. T. Pillai, V. N. Vaidya, and D. D. Sood, "Synthesis of yttrium aluminium garnet by the gel entrapment technique using hexamine," Materials Chemistry and Physics, vol. 46, no. 1, pp. 67-71, 1996.

[10] Y. C. Kang, Y. S. Chung, and S. B. Park, "Preparation of YAG:europium red phosphors by spray pyrolysis using a filterexpansion aerosol generator," Journal of the American Ceramic Society, vol. 82, no. 8, pp. 2056-2060, 1999.

[11] M. Nyman, J. Caruso, M. J. Hampden-Smith, and T. T. Kodas, "Comparison of solid-state and spray-pyrolysis synthesis of yttrium aluminate powders," Journal of the American Ceramic Society, vol. 80, no. 5, pp. 1231-1238, 1997.

[12] W. J. Dawson, "Hydrothermal synthesis of advanced ceramic powders," American Ceramic Society Bulletin, vol. 67, no. 10, pp. 1673-1678, 1988.

[13] D. F. K. Hennings, C. Metzmacher, and B. S. Schreinemacher, "Defect chemistry and microstructure of hydrothermal barium titanate," Journal of the American Ceramic Society, vol. 84, no. 1, pp. 179-182, 2001.

[14] A. T. Hunt, W. B. Carter, and J. K. Cochran Jr., "Combustion chemical vapor deposition: a novel thin-film deposition technique," Applied Physics Letters, vol. 63, no. 2, pp. 266-268, 1993.

[15] A. T. Hunt, J.K. Cochran, and W.B. Carter, "Combustion chemical vapor deposition of films and coatings," U.S. Patent Number 5,652,021, 1997.

[16] R. Maric, S. Seward, P. W. Faguy, and M. Oljaca, "Electrolyte materials for intermediate temperature fuel cells produced via combustion chemical vapor condensation," Electrochemical and Solid-State Letters, vol. 6, no. 5, pp. A91-A95, 2003.

[17] A. Yariv, Quantum Electronics, Wiley, New York, NY, USA, 3rd edition, 1989.

[18] J. E. Geusic, H. M. Marcos, and L. G. van Uitert, "Laser oscillations in nd-doped yttrium aluminum, yttrium gallium and gadolinium garnets," Applied Physics Letters, vol. 4, no. 10, pp. 182-184, 1964. 

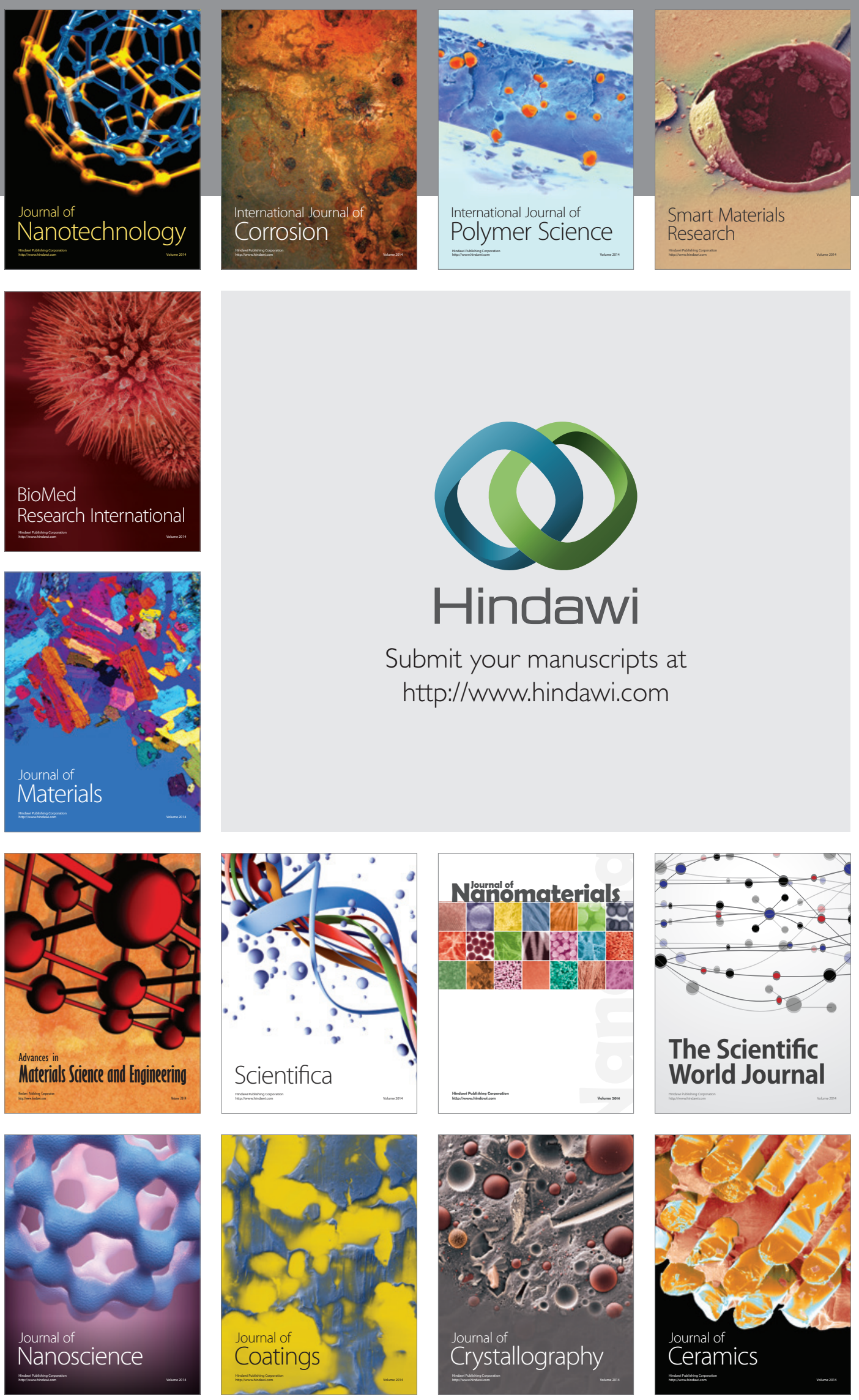

The Scientific World Journal

Submit your manuscripts at

http://www.hindawi.com

\section{World Journal}

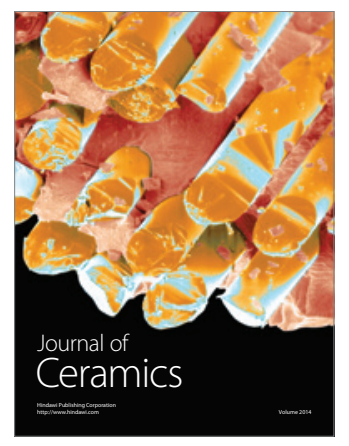

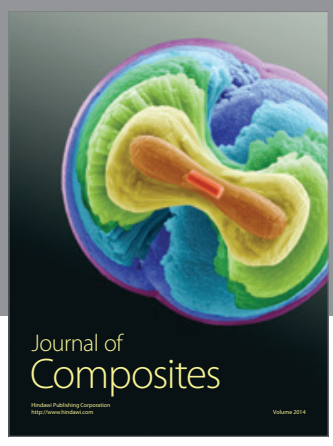
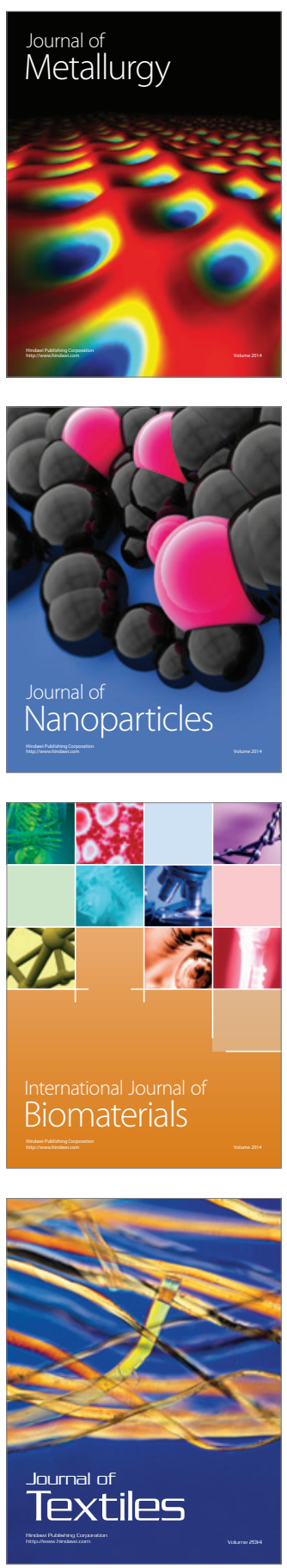